\title{
The relationship between mood and sleep in different female reproductive states
}

\author{
Elena Toffol ${ }^{1 *}$, Nea Kalleinen ${ }^{2,3}$, Anna Sofia Urrila ${ }^{1,4,5}$, Sari-Leena Himanen ${ }^{6,7}$, Tarja Porkka-Heiskanen, \\ Timo Partonen ${ }^{1}$ and Päivi Polo-Kantola ${ }^{2,8}$
}

\begin{abstract}
Background: Sleep is disrupted in depressed subjects, but it also deteriorates with age and possibly with the transition to menopause. The nature of interaction between mood, sleep, age and reproductive state is not well-defined. The aim of this study was to evaluate the relationship between mood and sleep among healthy women in different reproductive states.
\end{abstract}

Methods: We analyzed data from 11 younger (20-26 years), 21 perimenopausal (43-51 years) and 29 postmenopausal (58-71 years) healthy women who participated in a study on menopause, sleep and cognition. The 21-item Beck Depression Inventory (BDI) was administered to assess mood. Subjective sleep quality was assessed with the Basic Nordic Sleep Questionnaire (BNSQ). Objective sleep was measured with all-night polysomnography (PSG) recordings. Perimenopausal and younger women were examined during the first days of their menstrual cycle at the follicular phase.

Results: Among younger women, less arousals associated with higher BDI total scores $(p=0.026)$, and higher SWS percentages with more dissatisfaction $(p=0.001)$ and depressive-somatic symptoms ( $p=0.025)$, but with less depressive-emotional symptoms ( $p=0.001)$. In specific, less awakenings either from REM sleep or SWS, respectively, associated with more punishment $(p=0.005 ; p=0.036)$, more dissatisfaction $(p<0.001 ; p=0.001)$ and more depressive-somatic symptoms ( $p=0.001 ; p=0.009)$, but with less depressive-emotional symptoms $(p=0.002 ; p=0.003)$. In perimenopausal women, higher BNSQ insomnia scores $(p=0.005)$, lower sleep efficiencies $(p=0.022)$ and shorter total sleep times $(p=0.024)$ associated with higher BDI scores, longer sleep latencies with more depressive-somatic symptoms ( $p=0.032$ ) and longer REM latencies with more dissatisfaction $(p=0.017)$. In postmenopausal women, higher REM percentages associated with higher BDI total scores $(p=0.019)$ and more depressive-somatic symptoms $(p=0.005)$, and longer SWS latencies with more depressive-somatic symptoms $(p=0.030)$.

Conclusions: Depressive symptoms measured with the total BDI scores associated with sleep impairment in both perimenopausal and postmenopausal women. In younger women, specific BDI factors revealed minor associations, suggesting that the type of sleep impairment can vary in relation to different depressive features. Our data indicate that associations between sleep and depressed mood may change in conjunction with hormonal milestones.

Keywords: Perimenopause, Postmenopause, Reproduction, Sleep stage

\footnotetext{
* Correspondence: elena.toffol@thl.fi

${ }^{1}$ Department of Mental Health and Substance Abuse Services, National Institute for Health and Welfare (THL), Mannerheimintie 170, P.O. Box 30, Helsinki FI-00271, Finland

Full list of author information is available at the end of the article
} 


\section{Background}

Depressive symptoms are more common in women than in men [1,2]. Mood disorders, and in particular major depressive disorder (MDD), are also known to be twice as common in women as in men [3]. In addition, the onset, course and symptoms of depression differ between genders, as women are more likely to suffer from atypical depression, psychomotor retardation, anxiety/somatic symptoms, psychological distress, increased appetite and weight gain than men [2-6].

Although this gender difference persists throughout the female life-span, it seems to vary according to the reproductive state. The risk of depressive symptoms and that of disorders are higher during certain reproductive events such as the premenstrual phase, pregnancy and postpartum [7], and the transition to menopause [8,9]. In particular, during the climacterium there is an increased risk of experiencing low mood, irritability and difficulties in concentration, even after controlling for possible confounding factors [10-12], and up to 70-90\% of women report depressive symptoms [13].

Depressive symptoms and disorders are often accompanied by sleep disturbances. Indeed, sleep is typically disrupted in depressed subjects, with an abnormal amount and/or an abnormal distribution of rapid-eyemovement (REM) sleep and non-REM sleep [14], older individuals being more likely to suffer from middle or late insomnia and younger ones from hypersomnia [15-17]. Sleep impairment has been claimed as a prodromal symptom of depression, and some sleep abnormalities are considered as specific markers for MDD, such as impairment in sleep continuity, a lack of inhibition of REM sleep, and reduction in slow-wave sleep (SWS) $[14,18]$. Reciprocally, subjects suffering from insomnia or other sleep disturbances seem to be at a higher risk of developing MDD [19] and having recurrent depressive episodes [20]. However, whether sleep disturbances are part of the pathophysiology of depression or its consequences, it is not well understood $[21,22]$. Possibly, sleep disturbances and other psychiatric disorders share a common multifactorial etiology here [23].

Age and fluctuations of female sex hormones are likely to be part of this multifactorial etiology. Age is associated with a reduction of REM sleep and SWS [24-26], with an increase in time spent in lighter sleep stages and a general decrease in sleep efficiency especially in women [27]. On the other hand, aging is tightly interrelated with the transition to menopause, which in turn is characterized by an intense decrease of sex hormone levels. Women do commonly report sleep difficulties with an impaired subjective sleep quality and, to a lesser extent, also an impaired objective sleep quality during perimenopause and in postmenopause [28-32]. Recently,
Orff and colleagues [33] found that age and the reproductive status affect a different set of objective sleep parameters in women. One important study to focus on the relationship between reproductive state, sex hormone levels, sleep and depression [34], came to the conclusion that the association between hormonal changes and menopause could contribute to the increase in the sleep-endocrine alterations that are typically found in depression.

Given the complexity of the inter-relationship between mood, sleep, age and reproductive state, and the lack of clear evidence on this issue, the aim of our study was to evaluate the relationship between mood and sleep among healthy women in different reproductive states. We hypothesized that the relationship between lower mood and lower sleep quality would strengthen during and after the menopause, thereby partly explaining the increase in mood and sleep symptoms typically found in these periods. Mood was assessed not only with a conventional total depression score, but also with a factorial design for a detailed evaluation of the relationships in order to identify specific subcategories, if any, of depressive symptoms.

\section{Methods}

\section{Subjects and study design}

Altogether 61 women took part in the study: 11 younger women (age range 20-26 years), 21 perimenopausal women (age range 43-51 years) and 29 postmenopausal women (age range 58-71 years). This study was a part of a larger study investigating the effects of menopause on sleep and cognition [35]. In order to avoid the possible confounding effects of health-illness-related factors, healthy women only were selected for the study. Younger women were recruited via announcements at the University of Helsinki and studied in the Sleep Research Unit of the Institute of Biomedicine, University of Helsinki, Finland. The perimenopausal and postmenopausal women were enrolled through announcements in the local newspapers in the area of Turku and the studies were conducted in the Sleep Research Unit of the University in Turku, Finland. The Turku Sleep Research Unit served as the supervising and monitoring unit of the study. Perimenopausal status was defined by the serum follicle stimulating hormone (FSH) level $(<23 \mathrm{IU} / \mathrm{mL})$ and an ongoing regular or irregular menstrual cycle. Postmenopause was determined by age ( $\geq 58$ years) and at least 12 months of amenorrhea. None of the perimenopausal and postmenopausal women had used any hormone therapy (HT) in at least 12 months prior to or during the study, with the exception of one perimenopausal woman, in whom the washout period was five months. The younger women were all currently taking oral contraceptives (OCs) (ethinyl estradiol $20 \mathrm{ug}+$ desogestrel $0.15 \mathrm{mg}$, Mercilon ${ }^{\odot}$, Organon, Oss, the 
Netherlands). Perimenopausal and younger women were examined during the first days of their menstrual cycle at the follicular phase.

Presence of a mental, cardiovascular (except drugtreated balanced hypertension), endocrine (except drugtreated balanced hyperlipidemia), pulmonary, neurological or specific sleep disorder or malignancies was one of the exclusion criteria. Also women suffering from other conditions possibly affecting sleep (e.g. fibromyalgia or anemia) were excluded. Other exclusion criteria included the use of medication with central nervous system effects, alcohol abuse, smoking and excessive caffeine intake ( $>5$ cups of coffee per day). All women had regular sleepwake schedules and normal levels of blood hemoglobin, leucocytes, thrombocytes and serum thyrotropin. All women gave written informed consent after oral and written information. The study was approved by the Ethics Committee of Turku University Hospital and the University of Helsinki.

\section{Mood and sleep assessments}

The presence of current depressive symptoms was assessed via the 21-item Beck Depression Inventory (BDI) [36]. As the study sample consisted of healthy women of different age ranges, in addition to considering the BDI total score, a factor analysis was performed to identify the factors that could best explain the BDI items (Cronbach's alpha $=0.75$ ) in the whole sample. Because depressive disorders are notoriously multidimensional and characterized by different symptomatic patterns according to a number of correlates (including age and gender), a factor analysis was chosen as an approach to address depressive subcomponents. Four factors were identified and, on the basis of their most weighted loadings, named as "punishment/guilty feelings" (F1: guilty feelings, punishment feelings and self-dislike/ disappointment), "dissatisfaction" (F2: loss of pleasure, worries about one's health, feeling of looking ugly, sadness, lost interest in people), "depressive-emotional" (F3: lost appetite, crying, pessimism, sadness and feeling of worthlessness), and "depressive-somatic" (F4: indecisiveness, changed sleep pattern, lost interest in sex, past failure, impaired working capability, tiredness and irritability) patterns (Table 1). Items with no (\#9: suicidal ideation) or only one (\#19: weight loss) positive answer were excluded from the analyses.

Subjective insomnia (a sum score, with the range of 5-25) during the past three months was evaluated using the Basic Nordic Sleep Questionnaire (BNSQ) [37], with lower scores referring to lower levels of sleeping problems. The subjects kept a sleep diary during the three weeks before and one week after the study to verify their

Table 1 BDI factor analysis*

\begin{tabular}{|c|c|c|c|c|c|}
\hline & F1 & F2 & F3 & F4 & Sumsqr \\
\hline \#1 sadness & 0.099 & 0.445 & 0.304 & 0.268 & 0.372 \\
\hline \#2 pessimism & -0.027 & 0.032 & 0.306 & 0.213 & 0.141 \\
\hline \#3 past failure & 0.243 & 0.224 & 0.039 & 0.493 & 0.354 \\
\hline \#4 loss of pleasure & -0.178 & 0.980 & 0.025 & -0.005 & 0.993 \\
\hline \#5 guilty feelings & 0.390 & 0.175 & 0.258 & 0.227 & 0.301 \\
\hline \#6 punishment feelings & 0.928 & 0.286 & -0.005 & -0.239 & 1.000 \\
\hline \#7 self-dislike & 0.295 & -0.073 & -0.034 & 0.199 & 0.133 \\
\hline \#8 worthlessness & -0.022 & 0.172 & 0.289 & 0.147 & 0.135 \\
\hline \#10 crying & 0.062 & 0.051 & 0.322 & -0.031 & 0.111 \\
\hline \#11 irritability & 0.012 & 0.207 & 0.099 & 0.313 & 0.151 \\
\hline \#12 lost interest in people & 0.168 & 0.375 & 0.183 & 0.060 & 0.206 \\
\hline \#13 indecisiveness & -0.033 & 0.133 & 0.158 & 0.582 & 0.383 \\
\hline \#14 looking ugly & 0.115 & 0.445 & -0.019 & 0.238 & 0.269 \\
\hline \#15 impaired work capability & 0.074 & -0.149 & -0.036 & 0.482 & 0.262 \\
\hline \#16 changed sleep pattern & 0.153 & 0.087 & 0.218 & 0.554 & 0.385 \\
\hline \#17 fatigue or tiredness & 0.003 & 0.175 & -0.105 & 0.476 & 0.269 \\
\hline \#18 lost appetite & -0.033 & -0.110 & 0.984 & -0.104 & 0.993 \\
\hline \#20 worries about health & 0.295 & 0.486 & 0.006 & 0.099 & 0.333 \\
\hline \#21 lost interest in sex & -0.077 & 0.377 & 0.058 & 0.521 & 0.423 \\
\hline Sumsqr & 1.372 & 2.211 & 1.544 & 2.088 & \\
\hline
\end{tabular}

*Items with no (\# 9: suicidal ideation) or one (\# 19: weight loss) positive answer excluded from the analysis. Weighted loadings at each factor in boldface. Abbreviations: F1 punishment/guilty feelings, F2 dissatisfaction, F3 depressive-emotional symptoms, F4 depressive-somatic symptoms. 
sleep-wake schedules: all women had regular sleep-wake schedules $(10: 00-11: 00 \mathrm{pm}$ to $6: 00-7: 00 \mathrm{am})$. The women spent one adaptation night $(7: 30 \mathrm{pm}-8: 00 \mathrm{am}$, time in bed 11:00 pm - 7:00 am) in the sleep laboratory. In the following morning, a venous blood sample was taken for baseline serum FSH and estradiol (E2) measurements. In the following evening, the women returned to the laboratory at 7:30 pm for the baseline sleep recording. The all-night polysomnography (PSG) recordings consisted of continuous monitoring via electroencephalograms (EEG), electro-oculograms (EOG), a mandibular electromyogram (EMG) and an electrocardiogram (ECG, Embla ${ }^{\oplus}$, Medcare Flaga hf. Medical devices, Reykjavik, Iceland). Two EEG-channels (C3/A2, C4/A1) were used in younger women, while four EEGchannels (C3/A2, C4/A1, O1/A2 and O2/A2) were used in perimenopausal and postmenopausal women. Sleep stages were visually scored in 30-s epochs according to conventional criteria [38] by the same scorer (NK) and controlled by a senior scorer (PP-K). For the purpose of this study, three groups of sleep variables were considered as follows.

1. general sleep: sleep latency (period from lights off to sleep onset, defined as the appearance of three consecutive epochs of S1 or the first epoch of any other stage), total sleep time [sum of time spent in Stage 1 (S1), Stage 2 (S2), SWS, REM sleep and movement time (MT)], sleep efficiency (the percentage of total sleep time out of time in bed) and number of arousals (EEG $\alpha$-activity for at least three seconds [39]);

2. REM sleep: REM latency (the time from sleep onset to the first $30 \mathrm{~s}$ of the REM stage), REM percentage (the percentage of total time in bed, from lights off to lights on) and REM awakenings (the number of times entering wake stage from REM sleep);

3. SWS: SWS latency (the time from sleep onset to the first $30 \mathrm{~s}$ of the SWS), SWS percentage (the percentage of total time in bed, from lights off to lights on), SWS awakenings (the number of times entering wake stage from SWS) and total slow wave activity in NREM-sleep (SWA, 0.75-4 Hz) [40].

\section{Statistical analysis}

One perimenopausal and one postmenopausal woman were excluded from the analyses because of missing data. The normality of the distributions was tested with the Shapiro-Wilk test. Since the distributions of some variables were skewed, non-parametric Kruskal-Wallis test was performed to compare means between the three groups, using reproductive state as grouping variable (younger, perimenopausal or postmenopausal). When a significant difference was found, the pair-wise differences between each group were tested with Student's $t$-test (in the case of normal distribution) or Mann-Whitney test, as appropriate. The results were corrected according to the Bonferroni procedure. A $p$-value of $<0.05$ was considered significant.

A factor analysis was performed to identify the factors that best explained the variability within the BDI items. The factor matrix was computed according to the maximum likelihood principle and employing the algorithm presented by Jöreskog [41]. The standard orthogonal Varimax rotation was used to examine the degree of correlation among factors. The reliability estimates were computed according to the principles given by Cronbach [42] and the general measurement framework introduced by Tarkkonen [43] and developed further by Vehkalahti [44] using the RELIAB module of the Survo MM program [45].

Multivariable analysis was performed using generalized linear models to test the associations between sleep variables vs. BDI total score and each of the identified BDI factors. The analyses were performed separately on each group. The results were further controlled for age. Data were visually checked for outliers, defined as cases falling outside more than 1.5 times the interquartile range. All the multivariable analyses were repeated after exclusion of the identified outliers. Additionally, given the possible bias brought by the well-known tight interrelationship between sleep and depressive symptoms, multivariable analyses were repeated after exclusion of the sleep-related items (\#16 and \#17) from computation of the BDI total score. Descriptive and multivariable analyses were performed using SPSS/PASW software (version 18.0) (SPSS Inc., Chicago, IL, USA).

\section{Results}

Background characteristics of the participants are reported in Table 2. All the younger women had a BDI total score lower than 10 (range 0-5), indicating no depressive symptoms; one perimenopausal woman $(\mathrm{BDI}=11)$ and 6 postmenopausal women had a BDI total score ranging between 10 and $18(\mathrm{BDI}=10$ in two, $\mathrm{BDI}=11$ in one, $\mathrm{BDI}=13$ in two and $\mathrm{BDI}=15$ in one), indicating mild to moderate depressive symptoms. Postmenopausal women had higher mean BDI total score than younger women (6.3, SD $3.9 v s$. 1.8 , SD 1.7; $p=0.003)$, while no difference emerged between perimenopausal and younger women (4.1, SD 3.3 vs. 1.8, SD $1.7 ; p=0.147$ ), or between perimenopausal and postmenopausal women (4.1, SD 3.3 vs. 6.3, SD 3.9; $p=$ $0.147)$. The three groups differed in sleep as follows: when comparing with either perimenopausal or postmenopausal women, the younger women had longer total sleep time, better sleep efficiency, a greater SWS percentage, higher total SWA, less REM awakenings and less SWS awakenings. They also had longer REM latency than postmenopausal women. Additionally, younger women had lower 
Table 2 Background characteristics of the participants

\begin{tabular}{lccc}
\hline & Younger $(\mathbf{n}=\mathbf{1 1})$ & Perimenopausal $(\mathbf{n}=\mathbf{2 0})$ & Postmenopausal $(\mathbf{n}=\mathbf{2 8})$ \\
\hline Age $($ years $)$ & $23.1(1.6)$ & mean (SD) & $63.3(3.6)$ \\
FSH $(\mathrm{U} / \mathrm{L})$ & $3.8(2.8)$ & $47.7(2.3)$ & $76.2(29.2)$ \\
E2 $(\mathrm{pm} / \mathrm{L})$ & $91.8(87.3)$ & $10.6(4.8)$ & $31.2(10.6)$ \\
BMI $\mathrm{kg} / \mathrm{m}^{2}$ & $23.1(3.1)$ & $327.2(330.2)$ & $27.2(4.2)$ \\
BDI score (total) & $1.8(1.7)$ & $23.9(2.4)$ & $6.3(3.9)$ \\
F1 punishment/guilty feelings & $-0.26(0.08)$ & $0.1(3.3)$ & $0.01(1.0)$ \\
F2 dissatisfaction & $-0.48(0.06)$ & $0.18(1.26)$ & $0.10(1.05)$ \\
F3 depressive-emotional symptoms & $0.20(1.64)$ & $-0.20(0.14)$ & $0.07(1.07)$ \\
F4 depressive-somatic symptoms & $-0.62(0.38)$ & $-0.21(0.70)$ & $0.38(1.02)$ \\
\hline
\end{tabular}

Note: $\mathrm{BDI}=$ Beck depression inventory; $\mathrm{BMI}=$ body mass index; $\mathrm{E} 2$ = estradiol; $\mathrm{FSH}$ = follicle stimulating hormone.

insomnia scores at the BNSQ than both perimenopausal and postmenopausal women. Compared to perimenopausal women, postmenopausal women had higher BNSQ insomnia score. Results of pair-wise comparisons of the sleep variables in younger, perimenopausal and postmenopausal women have been published earlier in detail [40]; see also Additional file 1.

\section{BDI factors and insomnia}

Higher BDI total score was associated with higher BNSQ insomnia score in perimenopausal women $(B=0.457 ; 95 \%$ $\mathrm{CI}=0.139$ to $0.775 ; p=0.005$ ), also after controlling for age. However, the significance was lost when the sleep-related items (\#16 and \#17) were removed from the BDI total score $(\mathrm{B}=0.256 ; 95 \% \quad \mathrm{CI}=-0.017$ to $0.530 ; p=0.066)$. Higher scores at the depressive-emotional pattern $(p=0.043$ and $p=0.011$ ) in younger and perimenopausal women, at the depressive-somatic pattern $(p=0.036)$ in perimenopausal women, and at the punishment/guilty feelings factor ( $p=$ 0.010 ) in postmenopausal women were associated with higher BNSQ insomnia score. All the associations were maintained after removing of potential outliers. Further associations emerged after age adjustment: higher dissatisfaction score $(p=0.023$ and $p=0.042)$ was associated with higher insomnia score in younger and perimenopausal women, while the association with depressive-somatic symptoms lost the significance (Table 3).

\section{BDI factors and general sleep}

In younger women higher BDI total score was associated with lower amount of arousals $(B=-0.042 ; 95 \%$ $\mathrm{CI}=-0.079$ to $-0.005 ; p=0.026)$, and in perimenopausal women with lower sleep efficiency $(B=-0.159$; 95\% $\mathrm{CI}=-0.296$ to $-0.023 ; p=0.022)$ and shorter total sleep time $(B=-0.033 ; 95 \% \quad C I=-0.061$ to $-0.004 ; p=$ $0.024)$, also after controlling for age. The associations with sleep efficiency $(B=-0.097 ; 95 \% \quad C I=-0.210$ to
$0.016 ; p=0.002)$ and total sleep time $(B=-0.020 ; 95 \%$ $\mathrm{CI}=-0.043$ to $0.004 ; p=0.100)$ in perimenopausal women were lost after removing the sleep-related items (\#16 and \# 17) from the BDI total score. In perimenopausal women higher score at the depressive-somatic pattern was associated with longer sleep latency $(p=$ 0.032); however, the association was lost after controlling for age or after removing the outliers. No associations were found in postmenopausal women (Table 4). However, when outliers were removed, significant associations emerged between higher punishment/guilty feeling scores and shorter sleep time $(B=-0.012 ; 95 \%$ $\mathrm{CI}=-0.021$ to $-0.003 ; p=0.008)$ and lower sleep efficiency $(\mathrm{B}=-0.058 ; 95 \% \quad \mathrm{CI}=-0.100$ to $-0.015 ; p=$ 0.008 ) in postmenopausal women.

\section{BDI factors and REM sleep}

Higher BDI total score associated with a greater REM percentage in postmenopausal women $(B=0.301 ; 95 \%$ $\mathrm{CI}=0.049$ to $0.553 ; p=0.019)$ also after controlling for age, while no associations were found in the other groups. However, the association was lost when the sleeprelated items (\#16 and \#17) were removed from the BDI total score $(B=0.214 ; 95 \% \quad C I=-0.032$ to 0.459 ; $p=0.088)$. Lower scores at the punishment/guilty feelings $(p=0.005)$, dissatisfaction $(p<0.001)$ and depressive-somatic pattern $(p=0.001)$ and higher score at the depressiveemotional pattern $(p=0.002)$ were associated with higher amount of REM awakenings in younger women. Higher dissatisfaction $(p=0.017)$ score related to longer REM latency in perimenopausal women. Higher scores at the depressive-somatic pattern $(p=0.005)$ related to a greater REM percentage in postmenopausal women (Table 5), but the association was lost after removing of the outliers. All the above-mentioned associations, with the only exception of the one between lower score at the depressive-somatic pattern and higher amount of 
Table 3 Associations between BDI factors vs. subjective sleep quality (BNSQ insomnia)

\begin{tabular}{|c|c|c|c|c|c|c|c|c|c|c|c|c|c|}
\hline & \multicolumn{4}{|c|}{ Punishment/guilty feelings (F1) } & \multicolumn{3}{|c|}{ Dissatisfaction (F2) } & \multicolumn{3}{|c|}{$\begin{array}{l}\text { Depressive-emotional } \\
\text { (F3) }\end{array}$} & \multicolumn{3}{|c|}{ Depressive-somatic (F4) } \\
\hline & B & & $95 \% \mathrm{Cl}$ & $p$ & B & $95 \% \mathrm{Cl}$ & $p$ & B & $95 \% \mathrm{Cl}$ & $p$ & B & $95 \% \mathrm{Cl}$ & $p$ \\
\hline \multicolumn{14}{|c|}{ Younger women } \\
\hline \multirow{2}{*}{$\begin{array}{c}\text { BNSQ } \\
\text { insomnia }\end{array}$} & simple & -0.005 & $\begin{array}{l}-0.025 \text { to } \\
0.015\end{array}$ & 0.651 & -0.011 & $\begin{array}{c}-0.023 \text { to } \\
0.001\end{array}$ & 0.081 & 0.366 & $\begin{array}{l}0.011 \text { to } \\
0.720\end{array}$ & 0.043 & -0.039 & $\begin{array}{l}-0.133 \text { to } \\
0.055\end{array}$ & 0.416 \\
\hline & $\begin{array}{c}\text { age- } \\
\text { adjusted }\end{array}$ & -0.009 & $\begin{array}{c}-0.028 \text { to } \\
0.011\end{array}$ & 0.385 & -0.014 & $\begin{array}{l}-0.025 \text { to } \\
-0.002\end{array}$ & 0.023 & 0.442 & $\begin{array}{c}0.103 \text { to } \\
0.781\end{array}$ & 0.011 & -0.059 & $\begin{array}{c}-0.149 \text { to } \\
0.030\end{array}$ & 0.194 \\
\hline \multicolumn{14}{|c|}{ Perimenopausal women } \\
\hline \multirow{2}{*}{$\begin{array}{c}\text { BNSQ } \\
\text { insomnia }\end{array}$} & simple & -0.062 & $\begin{array}{c}-0.205 \text { to } \\
0.081\end{array}$ & 0.394 & 0.105 & $\begin{array}{c}-0.011 \text { to } \\
0.221\end{array}$ & 0.077 & 0.018 & $\begin{array}{l}0.004 \text { to } \\
0.032\end{array}$ & 0.011 & 0.078 & $\begin{array}{c}0.005 \text { to } \\
0.151\end{array}$ & 0.036 \\
\hline & $\begin{array}{c}\text { age- } \\
\text { adjusted }\end{array}$ & 0.046 & $\begin{array}{l}-0.134 \text { to } \\
0.226\end{array}$ & 0.618 & 0.159 & 0.006 to 0.312 & 0.042 & 0.025 & $\begin{array}{l}0.007 \text { to } \\
0.043\end{array}$ & 0.006 & 0.052 & $\begin{array}{l}-0.045 \text { to } \\
0.149\end{array}$ & 0.296 \\
\hline \multicolumn{14}{|c|}{ Postmenopausal women } \\
\hline \multirow{2}{*}{$\begin{array}{c}\text { BNSQ } \\
\text { insomnia }\end{array}$} & simple & 0.123 & $\begin{array}{c}0.029 \text { to } \\
0.216\end{array}$ & 0.010 & -0.054 & $\begin{array}{l}-0.161 \text { to } \\
0.053\end{array}$ & 0.323 & 0.003 & $\begin{array}{l}-0.109 \text { to } \\
0.115\end{array}$ & 0.955 & 0.088 & $\begin{array}{c}-0.013 \text { to } \\
0.189\end{array}$ & 0.086 \\
\hline & $\begin{array}{c}\text { age- } \\
\text { adjusted }\end{array}$ & 0.126 & $\begin{array}{c}0.035 \text { to } \\
0.217\end{array}$ & 0.007 & -0.056 & $\begin{array}{c}-0.163 \text { to } \\
0.051\end{array}$ & 0.306 & 0.006 & $\begin{array}{l}-0.104 \text { to } \\
0.117\end{array}$ & 0.913 & 0.086 & $\begin{array}{c}-0.014 \text { to } \\
0.187\end{array}$ & 0.091 \\
\hline
\end{tabular}

Associations between each BDI factor and BNSQ insomnia score were tested in each reproductive group separately via generalized linear models. Potential outliers included in the models.

Significant items are in italic.

Note: $\mathrm{BDI}=$ Beck depression inventory; $\mathrm{BNSQ}=$ basic Nordic sleep questionnaire; $95 \% \mathrm{Cl}=95 \%$ confidence intervals.

REM awakenings in younger women, were maintained after controlling for age.

\section{BDI factors and SWS}

No associations were found between BDI total score and any of the SWS variables. However, in younger women higher scores at the dissatisfaction $(p=0.001)$ and depressive-somatic pattern $(p=0.025)$, and lower score at the depressive-emotional pattern $(p=0.001)$ associated with a greater SWS percentage. Moreover, lower scores at the punishment/guilty feelings $(p=0.036)$, dissatisfaction $(p=0.001)$ and depressive-somatic pattern $(p=0.009)$, and higher score at the depressive-emotional pattern $(p=0.003)$ associated with higher amount of SWS awakenings. Higher score at the depressive-somatic pattern $(p=0.030)$ score related to longer SWS latency in postmenopausal women (Table 6). All the associations, except those of the depressive-somatic pattern in younger women, maintained their significance after controlling for age. When removing the outliers, a higher score at punishment/guilty feelings, but not at the depressive-somatic pattern, was associated with longer SWS latency $(B=0.095 ; 95 \% \quad C I=0.035$ to 0.155 ; $p=0.002)$ in postmenopausal women.

(The associations between mood symptoms and sleep quality in the three groups are illustrated in Additional files 2: Figure S1, Additional file 3: Figure S2 and Additional file 4: Figure S3).

\section{Discussion}

Associations between sleep stages or sleep quality and the clinically subthreshold depressive symptoms were evident both in perimenopausal and postmenopausal women. Higher depression scores associated with a lower subjective sleep quality (a higher insomnia score) as well as a lower objective sleep quality (a lower sleep efficiency and a shorter total sleep time), especially in perimenopausal women. Also, postmenopausal women with a higher BDI score had more REM sleep. On the contrary, the total BDI score was not sensitive enough to detect any significant associations with sleep in younger women.

To identify specific subgroups of depressive symptoms, factor analysis yielded a dual pattern of depression-withsleep associations in younger women with respect to the SWS amount and SWS or REM awakenings: more depressive-emotional symptoms were associated with a smaller SWS percentage and with more SWS awakenings and more REM sleep awakenings, whereas, vice versa, the associations towards the opposite directions were found concerning punishment, dissatisfaction and depressivesomatic symptoms. In perimenopausal women more dissatisfaction was associated with a longer REM latency, and more depressive-somatic symptoms with a worse sleep quality (higher BNSQ score and longer sleep latency). In addition, more depressive-somatic symptoms were associated with a greater REM percentage and a longer SWS latency in postmenopausal women. When the outliers or the sleep-related items (\#16 and \#17) were removed from the analyses, most of the associations with depressive somatic symptoms in perimenopausal and postmenopausal women were lost; rather, more punishment/guilty feelings were found to be associated with a worse sleep quality (higher 
Table 4 Associations^ between BDI factors vs. general sleep variables

\begin{tabular}{|c|c|c|c|c|c|c|c|c|c|c|c|c|}
\hline & \multicolumn{3}{|c|}{$\begin{array}{l}\text { Punishment/guilty feelings } \\
\text { (F1) }\end{array}$} & \multicolumn{3}{|c|}{ Dissatisfaction (F2) } & \multicolumn{3}{|c|}{$\begin{array}{l}\text { Depressive-emotional } \\
\text { symptoms (F3) }\end{array}$} & \multicolumn{3}{|c|}{$\begin{array}{l}\text { Depressive-somatic } \\
\text { symptoms (F4) }\end{array}$} \\
\hline & B & $95 \% \mathrm{Cl}$ & $p$ & B & $95 \% \mathrm{Cl}$ & $p$ & B & $95 \% \mathrm{Cl}$ & $p$ & B & $95 \% \mathrm{Cl}$ & $p$ \\
\hline \multicolumn{13}{|c|}{ Younger women } \\
\hline Sleep latency & 0.002 & $\begin{array}{l}-0.003 \text { to } \\
0.007\end{array}$ & 0.374 & 0.002 & $\begin{array}{l}-0.002 \text { to } \\
0.005\end{array}$ & 0.384 & -0.035 & $\begin{array}{l}-0.139 \text { to } \\
0.068\end{array}$ & 0.504 & 0.011 & $\begin{array}{l}-0.012 \text { to } \\
0.035\end{array}$ & 0.346 \\
\hline Sleep efficiency & 0.002 & $\begin{array}{l}-0.007 \text { to } \\
0.010\end{array}$ & 0.672 & 0.001 & $\begin{array}{l}-0.004 \text { to } \\
0.007\end{array}$ & 0.666 & -0.039 & $\begin{array}{l}-0.210 \text { to } \\
0.132\end{array}$ & 0.655 & 0.009 & $\begin{array}{l}-0.030 \text { to } \\
0.049\end{array}$ & 0.644 \\
\hline Total sleep time & 0.000 & $\begin{array}{l}-0.001 \text { to } \\
0.002\end{array}$ & 0.687 & 0.000 & $\begin{array}{l}-0.001 \text { to } \\
0.001\end{array}$ & 0.666 & -0.008 & $\begin{array}{l}-0.043 \text { to } \\
0.027\end{array}$ & 0.649 & 0.002 & $\begin{array}{l}-0.006 \text { to } \\
0.010\end{array}$ & 0.655 \\
\hline $\begin{array}{l}\text { Number of } \\
\text { arousals }\end{array}$ & 0.000 & $\begin{array}{l}-0.002 \text { to } \\
0.002\end{array}$ & 0.695 & 0.000 & $\begin{array}{l}-0.001 \text { to } \\
0.002 \\
\end{array}$ & 0.675 & -0.015 & $\begin{array}{l}-0.056 \text { to } \\
0.027\end{array}$ & 0.487 & -0.001 & $\begin{array}{c}-0.011 \text { to } \\
0.009\end{array}$ & 0.863 \\
\hline \multicolumn{13}{|c|}{ Perimenopausal women } \\
\hline Sleep latency & -0.009 & $\begin{array}{l}-0.044 \text { to } \\
0.026\end{array}$ & 0.611 & -0.010 & $\begin{array}{c}-0.039 \text { to } \\
0.020\end{array}$ & 0.521 & 0.001 & $\begin{array}{l}-0.003 \text { to } \\
0.004\end{array}$ & 0.793 & 0.019 & 0.002 to 0.037 & 0.032 \\
\hline Sleep efficiency & -0.004 & $\begin{array}{l}-0.063 \text { to } \\
0.055\end{array}$ & 0.896 & -0.028 & $\begin{array}{l}-0.077 \text { to } \\
0.022\end{array}$ & 0.276 & -0.005 & $\begin{array}{c}-0.011 \text { to } \\
0.001\end{array}$ & 0.075 & -0.023 & $\begin{array}{l}-0.054 \text { to } \\
0.009\end{array}$ & 0.159 \\
\hline Total sleep time & -0.001 & $\begin{array}{l}-0.013 \text { to } \\
0.012\end{array}$ & 0.905 & -0.006 & $\begin{array}{l}-0.016 \text { to } \\
0.005\end{array}$ & 0.295 & -0.001 & $\begin{array}{l}-0.002 \text { to } \\
0.000\end{array}$ & 0.082 & -0.005 & $\begin{array}{l}-0.011 \text { to } \\
0.002\end{array}$ & 0.155 \\
\hline $\begin{array}{l}\text { Number of } \\
\text { arousals }\end{array}$ & -0.002 & $\begin{array}{c}-0.014 \text { to } \\
0.011\end{array}$ & 0.806 & -0.005 & $\begin{array}{l}-0.016 \text { to } \\
0.005\end{array}$ & 0.290 & 0.000 & $\begin{array}{c}-0.001 \text { to } \\
0.001\end{array}$ & 0.823 & 0.005 & $\begin{array}{c}-0.002 \text { to } \\
0.011\end{array}$ & 0.167 \\
\hline \multicolumn{13}{|c|}{ Postmenopausal women } \\
\hline Sleep latency & 0.019 & $\begin{array}{l}-0.006 \text { to } \\
0.043\end{array}$ & 0.135 & -0.014 & $\begin{array}{l}-0.041 \text { to } \\
0.012\end{array}$ & 0.281 & 0.016 & $\begin{array}{l}-0.011 \text { to } \\
0.043\end{array}$ & 0.245 & 0.002 & $\begin{array}{l}-0.024 \text { to } \\
0.028\end{array}$ & 0.865 \\
\hline Sleep efficiency & -0.028 & $\begin{array}{l}-0.059 \text { to } \\
0.003\end{array}$ & 0.079 & 0.014 & $\begin{array}{c}-0.020 \text { to } \\
0.048\end{array}$ & 0.405 & -0.020 & $\begin{array}{l}-0.054 \text { to } \\
0.014\end{array}$ & 0.254 & 0.003 & $\begin{array}{c}-0.030 \text { to } \\
0.037\end{array}$ & 0.843 \\
\hline Total sleep time & -0.006 & $\begin{array}{c}-0.012 \text { to } \\
0.001\end{array}$ & 0.080 & 0.003 & $\begin{array}{l}-0.004 \text { to } \\
0.010\end{array}$ & 0.409 & -0.004 & $\begin{array}{c}-0.011 \text { to } \\
0.003\end{array}$ & 0.252 & 0.001 & $\begin{array}{c}-0.006 \text { to } \\
0.008\end{array}$ & 0.845 \\
\hline $\begin{array}{l}\text { Number of } \\
\text { arousals }\end{array}$ & -0.001 & $\begin{array}{c}-0.006 \text { to } \\
0.004\end{array}$ & 0.767 & 0.002 & $\begin{array}{c}-0.003 \text { to } \\
0.008\end{array}$ & 0.399 & -0.002 & $\begin{array}{c}-0.008 \text { to } \\
0.003\end{array}$ & 0.432 & -0.005 & $\begin{array}{c}-0.010 \text { to } \\
0.000\end{array}$ & 0.068 \\
\hline
\end{tabular}

Associations between each BDI factor and general sleep variables were tested in each reproductive group separately via generalized linear models. Potential outliers included in the models.

Significant items are in italic.

not age-adjusted.

Note: $\mathrm{BDI}=$ Beck depression inventory; $95 \% \mathrm{Cl}=95 \%$ confidence intervals.

scores of the subjective insomnia on BNSQ, a lower sleep efficiency, a shorter total sleep time, and a longer SWS latency) in postmenopausal women.

Previous studies focusing on the relationship between mood and sleep have typically used either diagnostic categories or sum scores of different depression assessment tools [46-49]. In the current study, we used the BDI total score which, however, produced limited associations, probably because of the generally good mental health status of our participants. The total BDI score was a sensitive enough index for detecting some previously reported associations between mood and sleep [33], especially in perimenopausal women, and to a lesser extent, in postmenopausal women. In specific, a relationship with the subjective sleep quality, known to be impaired in the context of depressive symptoms [33], was evident only in perimenopausal women. Additionally, a relationship between depressive symptoms and impairment in the objective sleep quality emerged both in perimenopausal (a shorter sleep time and a decreased sleep efficiency) and postmenopausal (a greater REM percentage) women, both findings being specific markers for depression $[18,33]$. However, it is of note that these associations lost their significance when the sleep-related items (\#16 and \#17) were removed from the analyses, further highlighting the tight inter-relationship between objective sleep impairment and depressive symptoms, and thus limiting any causal inference. The fact that the significance was lost after removing the sleep-related items may also suggest that the above-mentioned findings were mainly expression of poor sleep rather than of a true association between poor sleep and depressive symptoms in these reproductive groups.

The literature is rather consistent in reporting associations between depressive symptoms and sleep impairment already in young age $[50,51]$. However, in our study only one connection between the total BDI score and sleep was found in younger women, where hypersomnia rather than 
Table 5 Associations^ between BDI factors vs. REM sleep variables

\begin{tabular}{|c|c|c|c|c|c|c|c|c|c|c|c|c|}
\hline & \multicolumn{3}{|c|}{$\begin{array}{l}\text { Punishment/guilty feelings } \\
\text { (F1) }\end{array}$} & \multicolumn{3}{|c|}{ Dissatisfaction (F2) } & \multicolumn{3}{|c|}{$\begin{array}{l}\text { Depressive-emotional } \\
\text { symptoms (F3) }\end{array}$} & \multicolumn{3}{|c|}{$\begin{array}{l}\text { Depressive-somatic } \\
\text { symptoms (F4) }\end{array}$} \\
\hline & B & $95 \% \mathrm{Cl}$ & $p$ & B & $95 \% \mathrm{Cl}$ & $p$ & B & $95 \% \mathrm{Cl}$ & $p$ & B & $95 \% \mathrm{Cl}$ & $p$ \\
\hline \multicolumn{13}{|c|}{ Younger women } \\
\hline REM latency & 0.001 & 0.000 to 0.002 & 0.145 & 0.001 & 0.000 to 0.001 & 0.178 & -0.013 & $\begin{array}{l}-0.039 \text { to } \\
0.012\end{array}$ & 0.316 & 0.004 & -0.001 to 0.010 & 0.127 \\
\hline REM \% & -0.002 & -0.014 to 0.009 & 0.689 & 0.000 & -0.007 to 0.008 & 0.917 & -0.045 & $\begin{array}{l}-0.276 \text { to } \\
0.187\end{array}$ & 0.704 & -0.007 & -0.061 to 0.047 & 0.790 \\
\hline $\begin{array}{l}\text { REM } \\
\text { awakenings }\end{array}$ & -0.047 & $\begin{array}{l}-0.080 \text { to } \\
-0.014\end{array}$ & 0.005 & -0.037 & $\begin{array}{l}-0.056 \text { to } \\
-0.017\end{array}$ & $<0.001$ & 1.005 & 0.357 to 1.652 & 0.002 & -0.247 & $\begin{array}{l}-0.391 \text { to } \\
-0.103\end{array}$ & 0.001 \\
\hline \multicolumn{13}{|c|}{ Perimenopausal women } \\
\hline REM latency & 0.002 & -0.015 to 0.020 & 0.787 & 0.016 & 0.003 to 0.030 & 0.017 & 0.001 & 0.000 to 0.003 & 0.148 & -0.005 & -0.015 to 0.004 & 0.290 \\
\hline REM \% & 0.036 & -0.053 to 0.124 & 0.428 & -0.026 & -0.102 to 0.051 & 0.509 & -0.004 & $\begin{array}{l}-0.013 \text { to } \\
0.006\end{array}$ & 0.451 & -0.019 & -0.068 to 0.031 & 0.459 \\
\hline $\begin{array}{l}\text { REM } \\
\text { awakenings }\end{array}$ & -0.188 & -0.406 to 0.030 & 0.091 & 0.005 & -0.195 to 0.204 & 0.961 & -0.007 & $\begin{array}{c}-0.032 \text { to } \\
0.018\end{array}$ & 0.568 & -0.011 & -0.140 to 0.118 & 0.865 \\
\hline \multicolumn{13}{|c|}{ Postmenopausal women } \\
\hline REM latency & -0.001 & -0.016 to 0.013 & 0.855 & -0.008 & -0.023 to 0.006 & 0.269 & -0.001 & $\begin{array}{l}-0.017 \text { to } \\
0.015\end{array}$ & 0.895 & 0.003 & -0.012 to 0.018 & 0.713 \\
\hline REM \% & 0.004 & -0.066 to 0.074 & 0.911 & 0.022 & -0.052 to 0.095 & 0.558 & 0.038 & $\begin{array}{c}-0.036 \text { to } \\
0.112\end{array}$ & 0.317 & 0.091 & 0.028 to 0.154 & 0.005 \\
\hline $\begin{array}{l}\text { REM } \\
\text { awakenings }\end{array}$ & 0.025 & -0.092 to 0.143 & 0.672 & 0.064 & -0.057 to 0.186 & 0.297 & -0.052 & $\begin{array}{l}-0.177 \text { to } \\
0.073\end{array}$ & 0.414 & -0.076 & -0.193 to 0.040 & 0.200 \\
\hline
\end{tabular}

sleep impairment was connected with depressive symptoms. This could be due to the overall normal mood and sleep quality in young women. Because of these limited findings, we further performed a factor analysis, which grouped related BDI items into four specific categories with different depressive dimensions. As said, this was done in an attempt to better identify the different sub-components that are likely to characterize paucisymptomatic depressed women at different age and reproductive stages. When analyzing the associations between the BDI factors and sleep, a dual pattern of associations was consistently displayed in younger women: either the one between the depressive-emotional factor and more disrupted sleep, or that between punishment, dissatisfaction and depressive-somatic factors and less disrupted sleep. The depressive-emotional factor, which included feelings of sadness, hopelessness and worthlessness, was associated with a smaller SWS percentage and an increased number of awakenings from both SWS and REM sleep. The other factors, i.e. punishment (including also self-dislike), dissatisfaction (including loss of pleasure and worries about health), and depressive-somatic (expression of functional impairment) symptoms, had these associations in the opposite direction. Thus, it seemed that the depressive-emotional factor revealed a finding typical of depression, where depressed persons report (and have) a reduced sleep quality or insomnia [14,21]. On the other hand, the other BDI factors were associated with more hypersomnic features, suggesting that different depressive symptoms may be related to different dimensions of sleep impairment. In younger women more REM awakenings were associated with more depressive emotional symptoms, but with lower scores on the other depressive factors. This apparent contradiction could be explained by the fact that a high amount of REM sleep and sleep fragmentation are specific markers for depression. Emotional symptoms are likely to be the main dimension of depression in younger women, while other symptoms, including the somatic ones, are a major depressive feature in older individuals [52,53]. In this context, it is possible that the increased number of awakenings from REM sleep, expression of more fragmented sleep, results associated with the most significant depressive factor in young women (the emotional dimension) rather than with the remaining dimensions. This would be in line with the cognition of a tight interrelation between sleep (in particular REM sleep) and the emotional processing [54]. Another possible explanation to the apparent better sleep quality in relation to punishment, dissatisfaction and depressive-somatic factors 
Table 6 Associations^ between BDI factors vs. SWS variables

\begin{tabular}{|c|c|c|c|c|c|c|c|c|c|c|c|c|}
\hline & \multicolumn{3}{|c|}{$\begin{array}{l}\text { Punishment/guilty feelings } \\
\text { (F1) }\end{array}$} & \multicolumn{3}{|c|}{ Dissatisfaction (F2) } & \multicolumn{3}{|c|}{$\begin{array}{l}\text { Depressive-emotional } \\
\text { symptoms (F3) }\end{array}$} & \multicolumn{3}{|c|}{$\begin{array}{l}\text { Depressive-somatic } \\
\text { symptoms (F4) }\end{array}$} \\
\hline & B & $95 \% \mathrm{Cl}$ & $p$ & B & $95 \% \mathrm{Cl}$ & $p$ & B & $95 \% \mathrm{Cl}$ & $p$ & B & $95 \% \mathrm{Cl}$ & $p$ \\
\hline \multicolumn{13}{|c|}{ Younger women } \\
\hline SWS latency & 0.000 & -0.008 to 0.008 & 0.936 & -0.001 & -0.006 to 0.005 & 0.827 & 0.024 & -0.142 to 0.189 & 0.778 & 0.000 & -0.039 to 0.039 & 0.997 \\
\hline SWS \% & 0.011 & -0.002 to 0.023 & 0.093 & 0.012 & 0.005 to 0.018 & 0.001 & -0.344 & $\begin{array}{l}-0.542 \text { to } \\
-0.147\end{array}$ & 0.001 & 0.062 & 0.008 to 0.117 & 0.025 \\
\hline $\begin{array}{l}\text { SWS } \\
\text { awakenings }\end{array}$ & -0.106 & $\begin{array}{l}-0.205 \text { to } \\
-0.007\end{array}$ & 0.036 & -0.096 & $\begin{array}{l}-0.152 \text { to } \\
-0.040\end{array}$ & 0.001 & 2.701 & 0.913 to 4.490 & 0.003 & -0.585 & $\begin{array}{l}-1.024 \text { to } \\
-0.146\end{array}$ & 0.009 \\
\hline SWA total & 0.000 & -0.001 to 0.000 & 0.455 & 0.000 & 0.000 & 0.697 & 0.000 & 0.000 & 0.477 & -0.001 & -0.003 to 0.001 & 0.464 \\
\hline \multicolumn{13}{|c|}{ Perimenopausal women } \\
\hline SWS latency & -0.009 & -0.041 to 0.023 & 0.580 & -0.017 & -0.044 to 0.009 & 0.196 & -0.002 & -0.005 to 0.001 & 0.262 & 0.003 & -0.014 to 0.021 & 0.697 \\
\hline SWS \% & -0.022 & -0.117 to 0.073 & 0.656 & 0.028 & -0.052 to 0.109 & 0.492 & 0.005 & -0.005 to 0.015 & 0.338 & 0.020 & -0.032 to 0.072 & 0.442 \\
\hline $\begin{array}{l}\text { SWS } \\
\text { awakenings }\end{array}$ & -0.069 & -0.437 to 0.299 & 0.714 & 0.052 & -0.264 to 0.367 & 0.749 & 0.015 & -0.025 to 0.054 & 0.467 & 0.107 & -0.092 to 0.306 & 0.292 \\
\hline SWA total & -0.002 & -0.008 to 0.003 & 0.441 & -0.002 & -0.007 to 0.003 & 0.396 & 0.000 & -0.001 to 0.000 & 0.188 & -0.001 & -0.004 to 0.002 & 0.542 \\
\hline \multicolumn{13}{|c|}{ Postmenopausal women } \\
\hline SWS latency & 0.015 & -0.007 to 0.037 & 0.181 & -0.009 & -0.033 to 0.014 & 0.427 & 0.001 & -0.023 to 0.025 & 0.940 & 0.024 & 0.002 to 0.045 & 0.030 \\
\hline SWS \% & -0.026 & -0.075 to 0.024 & 0.305 & 0.006 & -0.047 to 0.058 & 0.835 & -0.030 & -0.083 to 0.023 & 0.271 & -0.040 & -0.089 to 0.010 & 0.115 \\
\hline $\begin{array}{l}\text { SWS } \\
\text { awakenings }\end{array}$ & -0.147 & -0.359 to 0.065 & 0.174 & 0.044 & -0.185 to 0.273 & 0.708 & -0.025 & -0.210 to 0.260 & 0.833 & -0.168 & -0.383 to 0.046 & 0.124 \\
\hline SWA total & -0.009 & -0.021 to 0.002 & 0.122 & 0.002 & -0.010 to 0.015 & 0.703 & -0.009 & -0.021 to 0.004 & 0.185 & -0.009 & -0.021 to 0.003 & 0.133 \\
\hline
\end{tabular}

in younger women might be that they have retained the ability to cope with depressive symptoms through improving their sleep quality. This hypothesis is partly supported by the findings by Talamini et al. [55]. In a sample of young healthy individuals (mean age 20 years, 72\% women) the authors found a bimodal pattern of response to an externally induced distress in terms of sleep quality. They concluded that, due to individual differences, some subjects may respond adaptively, i.e. improving their quality of sleep, while other individuals may respond in a maladaptive manner, i.e. with a reduction of their sleep quality. Based on their results, the authors suggested that a high SWS percentage may be associated with higher levels of "emotional dissipation" during sleep, while an increased number of awakenings to poor emotional dissipation. This is partly in line with our findings, where more (REM and SWS) awakenings and a smaller SWS percentage were related to higher emotional depressive symptoms, but lower scores on other depressive dimensions.

As sleep and its quality are known to deteriorate with age (including aging of the hypothalamus-pituitaryovarian system, i.e. with the transition into menopause), it can be hypothesized that this ability also deteriorates with, or is altered by aging. In fact, this dual pattern in the depression-sleep associations was not found among perimenopausal or postmenopausal women. It is therefore possible that these different patterns of associations reflect different symptomatic dimensions of depression at different ages. Based on our results, it seems that the emotional dimension is especially relevant in younger women, while the somatic component is transiently more evident in the perimenopausal group, and the affective dimension more specifically related to punishment and guilty feelings becomes relevant in postmenopausal women. However, as mentioned above, in this study the younger women in particular had low BDI scores, suggesting very limited and mild depressive symptoms. However, even subthreshold depression is known to be associated with a poor quality of life [56], and adolescents with subthreshold depressive conditions have not only an impaired functioning and higher levels of suicidality [57], but also a high risk of developing a major depressive episode [58].

Only in perimenopausal women, a connection between more dissatisfaction and a longer REM latency was found. This is partly in line with previous findings of a prolonged sleep latency in depressed subjects [14]. During the perimenopausal period women are prone to 
experience a variety of depressive and somatic symptoms [59-61] that may equally belong to the four different BDI factors identified in our study. Therefore, the total BDI score was more sensitive in identifying the associations with impaired sleep quality. In addition, a mismatch between subjective and objective sleep impairment in association with depressive symptoms and disorders has been reported during the menopausal transition, when the common report of sleep complaints and dissatisfaction with sleep not necessarily correlates with objective sleep impairment [62]. Furthermore, factors other than depression may have a more significant role in causing the sleep impairment typical for the perimenopausal period. For instance, gradually decreasing female sex hormone levels may directly affect sleep [63], and climacteric vasomotor symptoms are known to be associated with sleep impairment [30,32,64-67], independently of mood symptoms. In fact, not only depressive symptoms but also depressive disorders in perimenopausal and postmenopausal women could be due to the vasomotor climacteric symptoms, which impair sleep quality and quality of life in general, resulting in compromised psychological well-being and depression [68]. However, it is of note that some studies have found an antidepressant effect of hormone therapy in menopausal women irrespective of their vasomotor symptoms [69].

In our sample of postmenopausal women higher depressive-somatic symptoms were associated with more REM sleep and a longer SWS latency. Somatic complaints, which may in turn induce depression and impaired sleep, become more frequent with age, especially in women. Women complain more often than men about somatic symptoms associated with psychological distress [70], and the rates of "somatic depression", albeit low, are higher in women than in men [70,71]. As previously mentioned for the perimenopausal women, vasomotor symptoms tend to be associated with both depression and sleep disturbances [30,32,72] and may account for this finding. These associations with the depressive-somatic dimension were lost after removing the cases with more extreme values, this suggesting that the outliers in our sample, in alternative to being a mere cause of statistical noise, represented a subgroup of postmenopausal women suffering from some degree of residual climacteric (including depressive and somatic) symptoms. In addition, when excluding the outliers from the analyses, the mismatch between subjective and objective sleep impairment in association with depressive symptoms became even less evident in postmenopausal women, when more severe affective symptoms specifically related to guilty and punishment feelings associated with both impaired subjective (BNSQ insomnia) and objective (lower sleep efficiency, shorter total sleep time and longer SWS latency) sleep quality.
It warrants attention that the significance of the associations with the depressive-somatic pattern in perimenoapusal and postmenopausal women has to be interpreted with caution. In fact, the BDI sleep-related items (\#16 and \#17) were found to most markedly load at the depressive-somatic factor in our model; therefore, it cannot be ruled out that these findings are again mainly expression of poor sleep in perimenopausal and postmenopausal women. However, items other than the sleep-related ones (e.g., the lost interest in sex) remarkably contributed to the depressive-somatic pattern in the factor analysis, which could in fact account for the associations detected in the perimenopausal and postmenopausal groups.

It warrants attention that all the younger women in our sample were taking OCs, and therefore, it is not possible to rule out that our results are biased by the effect of hormonal contraception. Indeed, even though a number of studies have found no difference in terms of the subjective sleep quality between naturally cycling women and OC users [73,74], a modulation of sleep architecture by OC use has been shown [73-77]. Sleep alterations, such as a reduced sleep latency [77], and specifically a short REM sleep latency [31,74,76], a decrease in SWS [73-75] but an increase in stage 2 [73] and in REM sleep [77], reduced arousals and a tendency towards a better sleep efficiency [31,78] have been reported. Burdick and colleagues [77] reported that both depressed and healthy OC users had a shorter REM latency and less SWS than non-users. Moreover, healthy OC users, but not the depressed ones, had a shorter sleep latency and a greater REM percentage than non-users [77]. On the other hand, OC use may itself be associated with adverse effects on mood in a subgroup of vulnerable women $[79,80]$, and they are a common cause of OC discontinuation as well.

One of the limitations of this study is the small sample size. However, the numbers are in line with those of other studies on the same topic. Second, the study was carried out on a selected healthy population, thus preventing the generalization of the results to the general population. As women with previous mental disorders, such as depressive disorders, were excluded, our results cannot be extended to hold for depressed patients. In addition, the associations between sleep and depressive symptoms were limited, as only a minority of the study participants suffered from mild to moderate depressive symptoms; for this reason, it is plausible that some of our findings were in fact driven by the sleep symptoms themselves. However, given that the BDI sleep-related items loaded mostly at the somatic factor identified in our model, this limitation potentially concerns only the associations with the depressive-somatic pattern in perimenopausal and postmenopausal women. The characteristics of our study sample (a small sample, with a wide 
age range, that was screened for psychiatric illness and that reported few depressive symptoms) limit the applicability of the derived BDI factors to other (general and clinical) populations. Because of the recruitment criterion of three different reproductive states, the women also belonged to three different age groups. Hence, we were not able to clearly disentangle the effect of age from the effect of reproductive state on mood and sleep. However, after controlling for age within each reproductive group, part of the age effect could be taken into account. Even though we could not control for other confounding factors (e.g. stressful life events), the strict exclusion criteria allowed us to minimize the effects of factors such as irregular sleep-wake schedules, use of HT and other medications, smoking, and use of alcohol or drugs. Even though the state of mood and insomnia were assessed with a self-administered tool, nevertheless, the validity and reliability of the BDI and of the BNSQ scale has been widely demonstrated $[37,81]$. Furthermore, using the factor analysis procedure allowed us to better identify the associations that would have not emerged, if only the total BDI score was considered. Finally, the use of PSGs allowed us to specifically assess the objective sleep quality.

\section{Conclusions}

Our results support the evidence of a relationship between mood and sleep, with more severe depressive symptoms being linked to sleep impairment. The notable implication of our study is that when depressive symptoms are mild, the BDI total score may not be able to detect subtle connections. In these cases, a more detailed factor analysis may offer a valuable analytical tool. Moreover, the reproductive state should be taken into account when evaluating the effect of depression on sleep, since different related depression clusters may be relevant.

\section{Additional files}

\section{Additional file 1: Pairwise comparison of the participants} characteristics.

Additional file 2: Figure S1. Associations between BDI factors and subjective (BNSQ insomnia) and objective sleep quality in younger women (potential outliers included). All the BDI factors resulted associated with objective sleep quality. The depressive-emotional factor (F3) especially was associated with both subjective and objective sleep quality. Note: $\mathrm{BDI}=$ Beck depression inventory; BNSQ = basic Nordic sleep questionnaire; REM = rapid eye movement; SWS = slow wave sleep.

Additional file 3: Figure S2. Associations between BDI factors and subjective (BNSQ insomnia) and objective sleep quality in perimenopausal women (potential outliers included). The depressiveemotional (F3) and depressive-somatic (F4) factors were associated with subjective sleep quality; dissatisfaction (F2) and depressive-somatic symptoms (F4) were associated with objective sleep quality. Note: $\mathrm{BDI}=$ Beck depression inventory; BNSQ = basic Nordic sleep questionnaire; $\mathrm{REM}=$ rapid eye movement.

Additional file 4: Figure S3. Associations between BDI factors and subjective (BNSQ insomnia) and objective sleep quality in postmenopausal women (potential outliers included). Punishment (F1) was associated with subjective sleep quality and the depressive-somatic factor (F4) with objective sleep quality. Note: BDI = Beck depression inventory; BNSQ = basic Nordic sleep questionnaire; REM = rapid eye movement; SWS = slow wave sleep.

\section{Competing interests}

The authors declare that they have no competing interests.

\section{Authors' contributions}

SLH, NK, PP-K, ASU, TP and TP-H contributed to the conception and design of the study; NK, PP-K and ASU contributed to the acquisition of data. ET performed the statistical analyses and wrote the first draft of the manuscript. All the authors significantly contributed to the interpretation of the results and to the final draft of the manuscript, and critically revised it for its intellectual content. All authors read and approved the final manuscript.

\section{Acknowledgments}

The study was financially supported by a European Commission Grant (QLK6-CT-2000-00499), by the Väinö and Laina Kivi Foundation (to PP-K), The Finnish Menopause Society Foundation (to PP-K), The Finnish Medical Foundation (to PP-K and to ASU), The Turku University Foundation (to PP-K and NK) and by Finnish government EVO grant (to NK). Further financial support was provided by grants from the Research Foundation of the University of Helsinki, from the Center for International Mobility, and by the National Graduate School of Clinical Investigation (Helsinki, Finland) (to ET). We wish to thank Mrs Marjut Grainger for her help with the statistical analyses.

\section{Author details}

${ }^{1}$ Department of Mental Health and Substance Abuse Services, National Institute for Health and Welfare (THL), Mannerheimintie 170, P.O. Box 30, Helsinki FI-00271, Finland. 'Department of Physiology, Sleep Research Unit, University of Turku, Turku, Finland. ${ }^{3}$ Heart Center, Turku University Hospital and University of Turku, Turku, Finland. ${ }^{4}$ Department of Physiology, University of Helsinki, Helsinki, Finland. ${ }^{5}$ Department of Adolescent Psychiatry, Helsinki University Central Hospital, Helsinki, Finland. ${ }^{6}$ Department of Clinical Neurophysiology, Pirkanmaa Hospital District, Tampere, Finland. ${ }^{7}$ Faculty of Medicine, University of Tampere, Tampere, Finland. ${ }^{8}$ Department of Obstetrics and Gynecology, Turku University Hospital and University of Turku, Turku, Finland.

Received: 1 October 2013 Accepted: 10 June 2014

Published: 16 June 2014

\section{References}

1. Tibblin G, Bengtsson C, Furunes B, Lapidus L: Symptoms by age and sex: the population studies of men and women in Gothenburg, Sweden. Scand J Prim Health Care 1990, 8:9-17.

2. Kornstein SG, Schatzberg AF, Thase ME, Yonkers KA, McCulloughe JP, Keitner Gl, Gelenberg AG, Ryan CE, Hess AL, Harrison W, Davis SM, Keller MB: Gender differences in chronic major and double depression. J Affect Disord 2000, 60:1-11

3. Kuehner C: Gender differences in unipolar depression: an update of epidemiological findings and possible explanations. Acta Psychiatr Scand 2003, 108:163-174.

4. Angst J, Dobler-Mikola A: Do the diagnostic criteria and imipramine determine the sex ratio in depression? J Affect Disord 1984, 7:189-198.

5. Frank E, Carpenter LL, Kupfer DJ: Sex differences in recurrent depression: are there any that are significant? Am J Psychiatr 1988, 145:41-45.

6. Williams JB, Spitzer RL, Linzer M, Kroenke K, Hahn SR, De Gruy FV, Lazev A Gender differences in depression in primary care. Am J Obstet Gynecol 1995, 173:654-659.

7. Soares CN, Zitek B: Reproductive hormone sensitivity and risk for depression across the female life cycle: a continuum of vulnerability? J Psychiatry Neurosci 2008, 33:331-343.

8. Bromberger JT, Kravitz HM, Chang Y-F, Cyranowski JM, Brown C, Matthews KA: Major depression during and after the menopausal transition: study of women's health across the nation (SWAN). Psychol Med 2011, 41:1879-1888. 
9. Bromberger JT, Kravitz HM: Mood and menopause: findings from the study of women's health across the nation (SWAN) over 10 years. Obstet Gynecol Clin North Am 2011, 38:609-625.

10. Cohen IR, Wise PM: Effects of estradiol on the diurnal rhythm of serotonin activity in microdissected brain areas of ovariectomized rats. Endocrinology 1988, 122:2619-2625.

11. Cohen LS, Soares CN, Vitonis AF, Otto MW, Harlow BL: Risk of new onset of depression during the menopausal transition: the harvard study of moods and cycles. Arch Gen Psychiatry 2006, 63:385-390

12. Freeman EW, Sammel MD, Lin H, Nelson DB: Associations of hormones and menopausal status with depressed mood in women with no history of depression. Arch Gen Psychiatry 2006, 63:375-382.

13. Ohayon MM: Epidemiological study on insomnia in the general population. Sleep 1996, 19(suppl 3):7-15.

14. Armitage R: Sleep and circadian rhythms in mood disorders. Acta Psychiatr Scandinav 2007, 115(Suppl 443):104-115.

15. Garvey MJ, Schaffer CB: Are some symptoms of depression age dependent? J Affect Disord 1994, 32:247-251.

16. Husain MM, Rush AJ, Sackeim HA, Wisniewski SR, McClintock SM, Craven N, Holiner J, Mitchell JR, Balasubramani GK, Hauger R: Age-related characteristics of depression: a preliminary STAR*D report. Am J Geriatr Psychiatry 2005, 13:852-860.

17. Hegeman JM, Kok RM, van der Mast RC, Giltay EJ: Phenomenology of depression in older compared with younger adults: meta-analysis. Br J Psychiatry 2012, 200:275-281.

18. Steiger A, Kimura M: Wake and sleep EEG provide biomarkers in depression. J Psychiatr Res 2010, 44:242-252

19. Ford DE, Kamerow DB: Epidemiologic study of sleep disturbances and psychiatric disorders: an opportunity for prevention? JAMA 1989, 262:1479-1484.

20. Dryman A, Eaton WW: Affective symptoms associated with the onset of major depression in the community: findings from the US national institute of mental health epidemiological catchment area program. Acta Psychiat Scandinav 1991, 84:1-5.

21. Riemann D: Insomnia and comorbid psychiatric disorders. Sleep Med 2007, 8(suppl 4):S15-S20.

22. McNamara P, Auerbach S, Johnson P, Harris E, Doros G: Impact of REM sleep on distortions of self-concept, mood and memory in depressed/ anxious participants. J Affect Disord 2010, 122:198-207.

23. Voderholzer U, Al-Shajlawi A, Weske G, Feige B, Riemann D: Are there gender differences in objective and subjective sleep measures? a study of insomniacs and healthy controls. Depress Anxiety 2003, 17:162-172

24. Lauer C, Riemann D, Wiegand M, Berger M: From early to late adulthood: changes in EEG sleep of depressed patients and healthy volunteers. Biol Psychiatry 1991, 29:979-993.

25. Riemann D, Berger $M$, Voderholzer U: Sleep and depression - results from psychobiological studies: an overview. Biol Psychol 2001, 57:67-103.

26. Dijk DJ: Slow-wave sleep deficiency and enhancement: implications for insomnia and its management. World J Biol Psychiatry 2010, 11:22-28.

27. Ohayon MM, Carskadon MA, Guilleminault C, Vitiello MV: Meta-analysis of quantitative sleep parameters from childhood to old age in healthy individuals: developing normative sleep values across the human lifespan. Sleep 2004, 27:1255-1273.

28. Eichling PS, Sahni J: Menopause related sleep disorders. J Clin Sleep Med 2005, 1:291-300

29. Polo-Kantola P: Sleep and menopause. Womens Health 2007, 3:99-106.

30. Nowakowski S, Meliska CJ, Martinez LF, Parry BL: Sleep and menopause. CurNeurol Neurosci Rep 2009, 9:165-172.

31. Hachul H, Andersen ML, Bittencourt LRA, Santos-Silva R, Conway SG, Tufik S: Does the reproductive cycle influence sleep patterns in women with sleep complaints? Climateric 2010, 13:594-603.

32. Polo-Kantola P: Sleep problems in midlife and beyond. Maturitas 2011, 68:224-232.

33. Orff HJ, Meliska CJ, Lopez A, Martinez F, Sorenson D, Parry BL: Polysomnographic evaluation of sleep quality and quantitative variables in women as a function of mood, reproductive status, and age. Dialogues Clin Neurosci 2012, 14:413-424.

34. Antonijevic IA, Murck H, Frieboes R-M, Uhr M, Steiger A: On the role of menopause for sleep-endocrine alterations associated with major depression. Psychoneuroendocrinology 2003, 28:401-418.
35. Kalleinen N: Sleep and Menopause. Hormone therapy and sleep deprivation PhD thesis. Sarja D, Osa 819. Medica Odontologica. Turku: Turun Yliopisto; 2008.

36. Beck AT, Ward CH, Mendelson M, Mock J, Erbaugh: An inventory for measuring depression. Arch Gen Psychiatry 1961, 4:561-571.

37. Partinen $\mathrm{M}$, Gislason T: Basic nordic sleep questionnaire (BNSQ): a quantitated measure of subjective sleep complaints. J Sleep Res 1995, 4:150-155.

38. Rechtschaffen A, Kales A: A manual of standardized terminology, techniques and scoring systems for sleep stages of human subjects. Los Angeles, CA: Brain Information Service/Brain Research Institute, UCLA; 1968.

39. The Atlas Task Force, Bonnet M, Carley D, Carskadon M, Eaton P, Guilleminault C, Harper R, Hayes B, Hirshkowitz M, Ktonas P, Keenan S, Pressman M, Roehrs T, Smith J, Walsh J, Weber S, Westbrook P, Jordan B: ASDA report: EEG arousals: scoring rules and examples. Sleep 1992, 15:173-184

40. Kalleinen N, Polo-Kantola P, Himanen SL, Alhola P, Joutsen A, Urrila AS, Polo O: Sleep and the menopause - do postmenopausal women experience worse sleep than premenopausal women? Menopause Int 2008, 14:97-104

41. Jöreskog KG: Factor analysis by least-squares and maximum likelihood methods. In Statistical methods for digital computers. Volume 3. Edited by Enslein K, Ralston A, Wilf HS. New York: John Wiley \& Sons; 1977:125-153.

42. Cronbach $\sqcup$ : Coefficient alpha and the internal structure of tests. Psychometrika 1951, 16:297-334.

43. Tarkkonen L: On reliability of composite scales. Statistical studies 7. Helsinki: Finnish Statistical Society; 1987.

44. Vehkalahti K: Reliability of measurement scales: Tarkkonen's general method supersedes Cronbach's alpha. Statistical research reports 17. Helsinki: Finnish Statistical Society; 2000

45. Environment for creative processing of text and numerical data SURVO. WWW survo.fi/mm/english.html

46. Morphy H, Dunn KM, Lewis M, Boardman HF, Croft PR: Epidemiology of insomnia: a longitudinal study in a UK population. Sleep 2007, 30:274-280.

47. Jansson-Frojmark M, Lindblom K: A bidirectional relationship between anxiety and depression, and insomnia? a prospective study in the general population. J Psychosom Res 2008, 64:443-449.

48. Kamysheva E, Skouteris H, Wertheim EH, Paxton SJ, Milgrom J: A prospective investigation of the relationships among sleep quality, physical symptoms, and depressive symptoms during pregnancy. J Affect Disord 2010, 123:317-320.

49. Nyer M, Farabaugh A, Fehling K, Soskin D, Holt D, Papakostas Gl, Pedrelli P, Fava M, Pisoni A, Vitolo O, Mischoulon D: Relationship between sleep disturbance and depression, anxiety, and functioning in college students. Depress Anxiety 2013, 30:873-880.

50. Bruck D, Astbury J: Population study on the predictors of sleeping difficulties in young Australian women. Behav Sleep Med 2012, 10:84-95.

51. Frey $S$, Birchler-Pedross $A$, Hofstetter M, Brunner $P$, Götz T, Münch $M$, Blatte K, Knoblauch V, Wirz-Justice A, Cajochen C: Young women with major depression live on higher homeostatic sleep pressure than healthy controls. Chronobiol Int 2012, 29:278-294.

52. Gottfries CG: Is there a difference between elderly and younger patients with regard to the symptomatology and aetiology of depression? Int Clin Psychopharmacol 1998, 13(Suppl 5):S13-S18.

53. Shahpesandy H: Different manifestation of depressive disorder in the elderly. Neuro Endocrinol Lett 2005, 26:691-695.

54. Vandekerckhove M, Cluydts R: The emotional brain and sleep: an intimate relationship. Sleep Med Rev 2010, 14:219-226.

55. Talamini LM, Bringmann LF, de Boer M, Hofman WF: Sleeping worries away or worrying away sleep? physiological evidence on sleep-emotion interactions. PLoS One 2013, 8:e62480

56. Rodríguez MR, Nuevo R, Chatterji S, Ayuso-Mateos JL: Definitions and factors associated with subthreshold depressive conditions: a systematic review. BMC Psychiatry 2012, 12:181.

57. Balázs J, Miklósi M, Keresztény A, Hoven CW, Carli V, Wasserman C, Apter A, Bobes J, Brunner R, Cosman D, Cotter P, Haring C, losue M, Kaess M, Kahn JP, Keeley H, Marusic D, Postuvan V, Resch F, Saiz PA, Sisask M, Snir A, Tubiana A, Varnik A, Sarchiapone M, Wasserman D: Adolescent subthreshold-depression and anxiety: psychopathology, functional impairment and increased suicide risk. J Child Psychol Psychiatry 2013, 54:670-677. 
58. Bertha EA, Balázs J: Subthreshold depression in adolescence: a systematic review. Eur Child Adolesc Psychiatry 2013, doi:10.1007/s00787-013-0411-0.

59. Amore M, Di Donato P, Papalini A, Berti A, Palareti A, Ferrari G, Chirico C, De Aloysio D: Psychological status at the menopausal transition: an Italian epidemiological study. Maturitas 2004, 48:115-124.

60. Zöllner YF, Acquadro C, Schaefer M: Literature review of instruments to assess health-related quality of life during and after menopause. Qual Life Res 2005, 14:309-327.

61. Terauchi M, Hiramitsu S, Akiyoshi M, Owa Y, Kato K, Obayashi S, Matsushima E, Kubota T: Associations among depression, anxiety and somatic symptoms in peri- and postmenopausal women. J Obstet Gynaecol Res 2013, 39:1007-1013.

62. Young T, Rabago D, Zgierska A, Austin D, Laurel F: Objective and subjective sleep quality in premenopausal, perimenopausal, and postmenopausal women in the Wisconsin sleep cohort study. Sleep 2003, 26:667-672.

63. Kravitz HM, Zhao X, Bromberger JT, Gold EB, Hall MH, Matthews KA, Sowers MR: Sleep disturbance during the menopausal transition in a multiethnic community sample of women. Sleep 2008, 31:979-990.

64. Woodward S, Freedman RR: The thermoregulatory effects of menopausal hot flashes on sleep. Sleep 1994, 17:497-501.

65. Polo-Kantola P, Erkkola R, Helenius H, Irjala K, Polo O: When does estrogen replacement therapy improve sleep quality? Am J Obstet Gynecol 1998 178:1002-1009.

66. Polo-Kantola P, Erkkola R, Irjala K, Helenius H, Pullinen S, Polo O: Climacteric symptoms and sleep quality. Obstet Gynecol 1999, 94:219-224.

67. Ohayon MM: Severe hot flashes are associated with chronic insomnia. Arch Intern Med 2006, 166:1262-1268.

68. Campbell S, Whitehead M: Oestrogen therapy and the menopausal syndrome. Clin Obstet Gynaecol 1977, 4:31-47.

69. Schmidt PJ, Nieman L, Danaceau MA, Tobin MB, Roca CA, Murphy JH, Rubinow DR: Estrogen replacement in perimenopause-related depression: a preliminary report. Am J Obstet Gynecol 2000, 183:414-420.

70. Silverstein B: Gender differences in the prevalence of somatic versus pure depression: a replication. Am J Psychiatry 2002, 159:1051-1052.

71. Silverstein B: Gender difference in the prevalence of clinical depression: the role played by depression associated with somatic symptoms. Am Psychiatry 1999, 156:480-482.

72. Brown JP, Gallicchio L, Flaws JA, Tracy JK: Relations among menopausal symptoms, sleep disturbance and depressive symptoms in midlife. Maturitas 2009, 62:184-189.

73. Baker FC, Mitchell D, Driver HS: Oral contraceptives alter sleep and raise body temperature in young women. Pflugers Arch 2001, 424:729-737.

74. Baker FC, Waner Jl, Vieira EF, Taylor SR, Driver HS, Mitchell D: Sleep and 24 hour body temperatures: a comparison in young men, naturally cycling women and women taking hormonal contraceptives. J Physiol 2001, 530:565-574.

75. Ho MA: Sex hormones and the sleep of women. Sleep Research 1972 $1: 184$

76. Lee KA, Shaver JF, Giblin EC, Woods NF: Sleep patterns related to menstrual cycle phase and premenstrual affective symptoms. Sleep 1990, 13:403-409

77. Burdick RS, Hoffmann R, Armitage R: Short note: oral contraceptives and sleep in depressed and healthy women. Sleep 2002, 25:347-349.

78. Hachul H, Andersen ML, Bittencourt L, Santos-Silva R, Tufik S: A populationbased survey on the influence of the menstrual cycle and the use of hormonal contraceptives on sleep patterns in São Paulo, Brazil. Int J Gynaecol Obstet 2013, 120:137-140.

79. Oinonen KA, Mazmanian D: To what extent do oral contraceptives influence mood and affect? J Affect Disord 2002, 70:229-240.

80. Rapkin AJ, Morgan M, Sogliano C, Biggio G, Concas A: Decreased neuroactive steroids induced by combined oral contraceptive pills are not associated with mood changes. Fertil Steril 2006, 85:1371-1378.

81. Beck AT, Steer RA, Carbin GM: Psychometric properties of the beck depression inventory: twenty-five years of evaluation. Clin Psychol Rev 1988, 8:77-100.

doi:10.1186/1471-244X-14-177

Cite this article as: Toffol et al:: The relationship between mood and sleep in different female reproductive states. BMC Psychiatry 2014 14:177.

\section{Submit your next manuscript to BioMed Central and take full advantage of:}

- Convenient online submission

- Thorough peer review

- No space constraints or color figure charges

- Immediate publication on acceptance

- Inclusion in PubMed, CAS, Scopus and Google Scholar

- Research which is freely available for redistribution
C Biomed Central 